\title{
Prevalence of Metabolic Syndrome among Obese Children and Adolescents
}

\author{
MOHSIN $F^{\mathrm{a}}$, BAKI $\mathrm{A}^{\mathrm{b}}$, NAHAR J ${ }^{\mathrm{c}}$, AKHTAR $\mathrm{S}^{\mathrm{d}}$, BEGUM T ${ }^{\mathrm{e}}$, AZAD K ${ }^{\mathrm{f}}$, NAHAR $\mathrm{N}^{\mathrm{g}}$
}

\begin{abstract}
:
Objectives: The Prevalence and magnitude of childhood obesity are increasing dramatically. The study was undertaken to see the prevalence of metabolic syndrome among children and adolescents with obesity, attending the Paediatric Endocrine OPD, BIRDEM.
\end{abstract}

Methods: A cross sectional study was conducted from January 2006 to December 2008 among obese children and adolescents (6-18 years) attending Paediatric endocrine out patient department of BIRDEM. Children with any other endocrine disorder, dysmorphism/syndrome were excluded. Obesity was defined as BMIe" $95^{\text {th }}$ percentile for age and sex using CDC growth chart. Children underwent two-hour oral glucose tolerance test, anthropometric and blood pressure measurement. Fasting serum insulin and lipid profile were measured. Impaired glucose tolerance (IGT) was defined as fasting plasma glucose (FPG) $<7 \mathrm{mmol} / \mathrm{L}$ and $2 \mathrm{hr}$ post glucose load e"7.8 $\mathrm{mmol} / \mathrm{L}$ to $<11.1 \mathrm{mmol} / \mathrm{L}$. Metabolic syndrome was identified if 3 or more of following criteria were met: BMI > 97th percentile for age and sex,

a. Fauzia Mohsin, MBBS, FCPS, Associate professor, Department of Paediatrics, Bangladesh Institute of Research and Rehabilitation in Diabetes, Endocrine and Metabolic Disorders (BIRDEM) and Ibrahim Medical College

b. Abdul Baki, MBBS, MD, Registrar, Department of Pardiatrics, BIRDEM and Ibrahim Medical College

c. Jebun Nahar, MBBS, DCH, MD, Associate Professor and Resident Physician, Department of Paediatrics, BIRDEM and Ibrahim Medical College

d. Shahida Akhter, MBBS, FCPS, Associate Professor, Department of Paediatrics, BIRDEM and Ibrahim Medical College

e. Tahmina Begum, FCPS, MD, M M Ed, Professor and Head, Department of Paediatrics, BIRDEM and Ibrahim Medical College

f. Kishwar Azad, LRCP, MRCS, FCPS, MSc, Senior Honorary Consultant, Department of Paediatrics, BIRDEM and Ibrahim Medical College

g. Nazmun Nahar, MBBS, FCPS, FRCP, Professor, Department of Paediatrics, BIRDEM and Ibrahim Medical Colllege

Address of Correspondence: Dr. Fauzia Mohsin, Department of Paediatrics, Bangladesh Institute of Research and Rehabilitation in Diabetes, Endocrine and Metabolic Disorders (BIRDEM) and Ibrahim Medical College, 122, Kazi Nazrul Islam Avenue, Shahabag; Dhaka-1000; Bangladesh. Tel: 880-1713063141 (Mobile), Tel: 8802-8855032 (H), Tel: 880-2-9661551-60/2371, Fax: 880-2-966781 Email: fauzia_mohsin@yahoo.com

Received: May 30, 2011

Accepted: June 30, 2011 high triglyceride (TGe"150 mg/dl), low high-density lipoprotein cholesterol (HDL cholesterol $<40 \mathrm{mg} / \mathrm{dl}$ ), Systolic or diastolic blood pressure $>95$ th percentile for age and sex, IGT.

Results: A total of 161 children presented with obesity. Male to female ratio was 1.3:1. Mean age was 10.3 \pm 2.5 years. Metabolic syndrome was identified in $36.6 \%$ subjects (59 out of 161, twentyfive male and 34 female). Higher BMI and hip circumference, systolic and diastolic hypertension, high TG low HDL cholesterol and IGT were significantly associated with metabolic syndrome.

Conclusions: The prevalence of metabolic syndrome is high among obese children and adolescents. Factors contributing towards obesity needs to be identified and strategies should be planned for prevention and management of this health problem.

Key Words: Obesity, Children, Adolescent, Metabolic syndrome

(Birdem Med J 2011; 1(1): 21-25)

\section{Introduction:}

The prevalence of childhood obesity has risen several times in past few decades in developed as well as developing countries. ${ }^{1,2}$ Urbanization, unhealthy diets and increased sedentary lifestyles have contributed to the increased prevalence of childhood obesity, particularly in developing countries. ${ }^{3}$ The prevalence of obesity was found to be $17.9 \%$ and that of overweight was $23.6 \%$ among affluent school children and adolescents in Dhaka. ${ }^{4}$ Childhood obesity is associated with several metabolic and endocrine derangements including hyperinsulinaemia, glucose intolerance, hypertension and dislipidaemia that predispose individuals to early development of cardiovascular disease and type 2 diabetes mellitus (T2DM).The clustering of these cardiovascular and metabolic risk factors have been identified as metabolic syndrome. 5,6 The prevalence of metabolic syndrome varied from $28.7 \%$ to $50 \%$ in various studies among obese children and adolescents. ${ }^{7-9}$ We have found a high rate of Impaired glucose tolerance (IGT) and dislipidaemia in obese children and adolescents. ${ }^{10}$ Limited data is 
available from our country on metabolic syndrome in children and adolescents and hence the present study was conducted to see the prevalence of metabolic syndrome among obese children and adolescents.

\section{Methods:}

A cross sectional study was conducted from January 2006 to December 2008 among children and adolescents attending Paediatric endocrine outpatient Department (OPD) of BIRDEM with the complaints of excessive weight gain.

Obese children and adolescents aged 6-18 years were included in the study. Children with any other endocrine disorder, dysmorphism/syndrome were excluded. History was obtained from all subjects and physical examination was performed. Blood pressure was measured using appropriate sized cuff encircling at least $2 / 3^{\text {rd }}$ of upper arm. Anthropometric measurement of weight, standing height, waist and hip circumference were taken. Weight was measured using a bathroom scale to the nearest 100 gram. Standing height was measured with stadiometer and measurement was done to nearest $0.1 \mathrm{~cm}$. The waist circumference was measured at the level midway between the lower rib margin and iliac crest, at the level of umbilicus with the child breathing out gently. The hip circumference was measured at the maximum width over the buttocks at the level of the greater trochenter with a plastic measuring tape. The body mass index (BMI) was calculated as weight in kilogram (Kg) divided by square of the height in meter. Obesity was defined as BMIe"95 ${ }^{\text {th }}$ centile for age and sex using CDC growth chart. ${ }^{11}$

Children underwent two-hour oral glucose tolerance test (OGTT). Patients were kept on unrestricted carbohydrate diet for at least three consecutive days prior to the test and kept fasting for 8-14 hours on the night before doing the test. Blood was collected at " 0 minute” for estimation of glucose, serum insulin, lipid profile and other relevant investigations. Then anhydrous glucose was given in the amount of $1.75 \mathrm{mg} /$ kg body weight (maximum 75 gram) dissolved in water for OGTT. The second sample of blood glucose was collected at "120 minute". Estimation of blood glucose and lipid profile was done by enzymatic colorimetric method using multichannel autoanalyzer. Impaired glucose tolerance (IGT) was defined as fasting plasma glucose (FPG) $<7 \mathrm{mmol} / \mathrm{L}$ and $2 \mathrm{hr}$ post glucose load $\geq 7.8 \mathrm{mmol} / \mathrm{L}$ to $<11.1 \mathrm{mmol} / \mathrm{L} .{ }^{12}$ Diabetes Mellitus (DM) was defined as FPGe" $7 \mathrm{mmol} / \mathrm{L}$ or $2 \mathrm{hr}$ post glucose loade" $11.1 \mathrm{mmol} / \mathrm{L} .{ }^{12}$ Insulin resistance index (Ins-resistance index)was determined by homeostatic model and calculated as the product of the fasting plasma insulin level ( $\mu \mathrm{Unit} / \mathrm{ml}$ ) and the fasting plasma glucose level (mmol/l),divided by 22.5. ${ }^{13}$ Total cholesterole" 200mg/dl,Triglyceride (TG) e"150 mg/dl, low-density lipoprotein cholesterol(LDL cholesterol) e” 130mg/dl, high-density lipoprotein cholesterol (HDL cholesterol $)<40 \mathrm{mg} / \mathrm{dl}$ were designated abnormal.. ${ }^{14.15}$ Hypertension was defined as BPe"95 ${ }^{\text {th }}$ percentile for age and $\operatorname{sex}^{16}$.

Metabolic syndrome(MT) was identified if 3 or more of following criteria were met: BMI > 97th percentile, high TG, low HDL cholesterol , Systolic or diastolic blood pressure $>95$ th percentile, IGT. ${ }^{9}$

Data were analysed using SPSS software ( version 12).Student $T$ test and Chi-Square test was performed when applicable. $\mathrm{P}$ value of $<0.05$ was considered significant. Descriptive statistics were reported as mean ( \pm SD).

\section{Results:}

A total of 161 children presented with obesity. Male to female ratio was 1.3:1. Mean age was $10.3 \pm 2.5$ years. Metabolic syndrome was identified in $36.6 \%$ of subjects(59 out of 161). There was a female predominance with 34 female and 25 male (female to male ratio $1.36: 1$ ).

Clinical and biochemical data of children with metabolic syndrome (Group 1) and without metabolic syndrome (group 2) are shown in table 1. While comparing the clinical phenotype and biochemichal data of obese children and adolescents with metabolic syndrome (group 1) and without metabolic syndrome (group 2) BMI, hip circumference, systolic blood pressure, diastolic blood pressure, Blood glucose at 2 hour of OGTT and triglyceride was found significantly higher among the former group. HDL cholesterol was lower in group 1 compared to that of group 2. Fasting serum insulin was measured in 34 subjects. Mean serum insulin level was not significantly different among the two groups. Mean insulin-resistance index (Ins-resistance index) was higher in the former group, although it was not statistically significant. The clinical and metabolic profile of children and adolescents of both groups are shown in TableI. 
Table I

Showing clinical and biochemical data of children with metabolic syndrome (group1) and without metabolic syndrome (group 2)

\begin{tabular}{lccc}
\hline & Group 1 & Group 2 & p-value \\
\hline Age(Yrs) & $10.56( \pm 1.95)$ & $10.40( \pm 2.63)$ & 0.73 \\
Weight (Kg) & $60.15( \pm 14.77)$ & $56.07( \pm 16.17)$ & 0.14 \\
Height (cm) & $143.48( \pm 12.27)$ & $142.68( \pm 14.84)$ & 0.74 \\
BMI kg/m & $29.02( \pm 3.76)$ & $27.46( \pm 3.74)$ & 0.02 \\
Waist (cm) & $87.80( \pm 9.81)$ & $85.41( \pm 10.33)$ & 0.25 \\
Hip (cm) & $96.66( \pm 10.63)$ & $91.36( \pm 11.12)$ & 0.02 \\
Waist/hip & $0.90( \pm 0.05)$ & $0.93( \pm 0.09)$ & 0.06 \\
Systolic BP(mm of Hg) & $114.79( \pm 13.02)$ & $107.58( \pm 14.58)$ & 0.005 \\
Diastolic BP(mm of Hg) & $74.93( \pm 10.11)$ & $68.98( \pm 9.53)$ & 0.001 \\
Fasting Plasma glucose(mmol/l) & $4.85( \pm 0.59)$ & $4.76( \pm 0.63)$ & 0.41 \\
Plasma glucose at 2 hr of OGTT(mmol/l) & $7.26( \pm 1.27)$ & $6.73( \pm 1.26)$ & 0.02 \\
Insulin $(\mu U / m l)$ & $22.05( \pm 8.68)$ & $21.91( \pm 15.35)$ & 0.97 \\
Ins-resistance index & $4.72( \pm 1.94)$ & $3.84( \pm 2.24)$ & 0.27 \\
TG(mg/dl) & $200.89( \pm 83.96)$ & $131.03( \pm 55.08)$ & 0.00 \\
Cholesterol (mg/dl) & $182.14( \pm 36.05)$ & $181.91( \pm 41.88)$ & 0.97 \\
LDL cholesterol(mg/dl) & $106.31( \pm 32.89)$ & $112.06( \pm 39.40)$ & 0.39 \\
HDL cholesterol(mg/dl) & $35.75( \pm 7.43)$ & $42.34( \pm 9.86)$ & 0.00 \\
\hline
\end{tabular}

Among the 59 children and adolescents with metabolic syndrome $\mathrm{BMI}>97^{\text {th }}$ percentile was found in 51(86.4\%), low HDL-Cholesterol in 44 (74.5\%), high TG in 41(69.4\%), IGT in 19 (32.2\%), diastolic hypertension in 18 (30.5\%) and systolic hypertension in $16(27.1 \%)$ of subjects. Fig I shows the frequency of various components of metabolic syndrome.

On Chi-square analysis BMI $>97^{\text {th }}$ percentile $(p=0.01)$, high TG $(p=0.000)$, low HDL cholesterol $(p=0.000)$, $\operatorname{IGT}(p=0.000)$, Systolic hypertension $(p=0.008)$ and diastolic hypertension( $\mathrm{p}=0.02)$ were significantly associated with metabolic syndrome. No association was found with family history of diabetes, presence of high cholesterol and high LDL cholesterol (Table II)

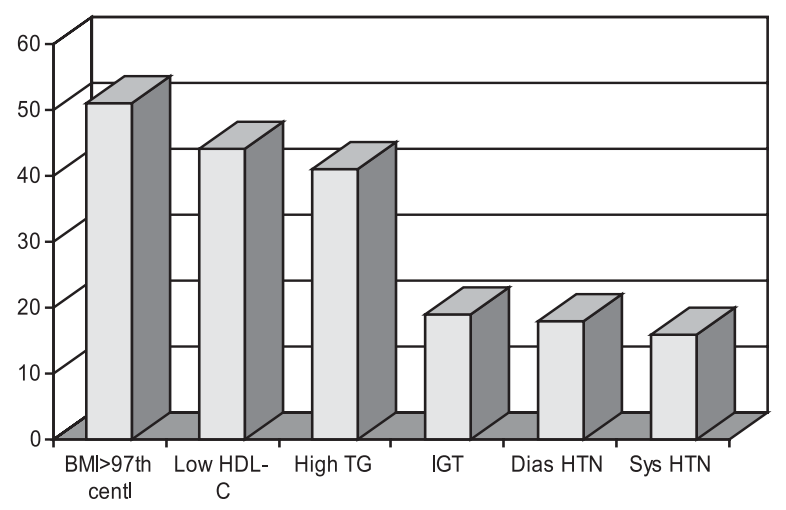

Fig.-I: Showing frequency of various components of metabolic syndrome

\section{Table II}

Showing association of various factors in obese subjects with and without metabolic syndrome (MetS)

\begin{tabular}{lccc} 
Characteristics & With Met S, $\mathrm{n}=59 \mathrm{n}(\%)$ & Without Met S, $\mathrm{n}=102 \mathrm{n}(\%)$ & P value \\
\hline BMI>97 ${ }^{\text {th }}$ percentile & $51(86.44)$ & $71(69.64)$ & 0.01 \\
High triglyceride level & $41(69.49)$ & $23(22.54 \%)$ & 0.000 \\
High total cholesterol & $17(28.81)$ & $26(25.49 \%)$ & 0.64 \\
Low HDL cholesterol & $44(74.57)$ & $35(34.31)$ & 0.000 \\
High LDL cholesterol & $13(22.03)$ & $24(23.52)$ & 0.82 \\
Family H/O diabetes present & $32(54.23)$ & $46(45.09)$ & 0.48 \\
IGT present & $19(32.20)$ & $8(7.84)$ & 0.000 \\
Systolic hypertension present & $16(27.11)$ & $11(10.78)$ & 0.008 \\
Diastolic hypertension present & $18(30.50)$ & $16(15.68)$ & 0.02 \\
\hline
\end{tabular}




\section{Discussion:}

In our study the prevalence of metabolic syndrome in obese children and adolescence is $36.6 \%$. This is comparable with the figures of $28.7 \%$ to $37.5 \%$ reported in other studies carried out among obese children and adolescents. ${ }^{7,17,18}$ In one study in USA the prevalence of metabolic syndrome increased with the severity of obesity, it was $38.7 \%$ in moderately obese subjects (a BMI z-score of 2 to 2.5 ) and reached $49.7 \%$ in severely obese subjects(a BMI z-score above 2.5). ${ }^{9}$

The metabolic syndrome in adults is defined as a Cluster of cardiovascular and diabetes risk factors including abdominal obesity (expressed by waist circumference), dyslipidaemia, glucose intolerance and hypertension. ${ }^{3}$ There are a range of published metabolic syndrome definition in paediatrics ${ }^{7-9,17,19}$ and the result of study on metabolic syndrome in children and adolescent can vary with the criteria used to define metabolic syndrome. We have adopted the criteria from Weiss et al ${ }^{9}$ where obesity was defined on the basis of BMI instead of waist circumference. Waist circumference and waist hip ratio are difficult to interpret in children as body proportion changes during childhood and adolescents. We have slightly modified the criteria for abnormal TG and HDL cholesterol level. A TG level of more than $95^{\text {th }}$ percentile and HDL cholesterol level of less than $5^{\text {th }}$ percentile for their population was designated as abnormal by Weiss. In our study a TGe"150mg/dl and HDL cholesterol $<40 \mathrm{mg} / \mathrm{dl}$ was taken as abnormal as used by others in case of children and adolescents. ${ }^{14}$

In our study BMI was significantly higher in children with metabolic syndrome as found in other studies $7,9,20$ Metabolic syndrome was more frequent in female than males, which does not agree with the data reported in other studies of similar age. ${ }^{7-9}$ A study carried out among adult population in Bangladesh has found higher prevalence of metabolic syndrome in females using International Diabetes Foundation (IDF) criteria. ${ }^{21} \mathrm{We}$ did not find age, family history of diabetes to be associated with metabolic syndrome in agreement with Cook et al. ${ }^{7}$ In the present study the waist-hip ratio in obese children in all age group was more than 0.9 indicating abdominal adiposity. Waist -hip ratio is an excellent predictor of abnormalities of lipids and glucose metabolism in the adult population and similar correlation have been made for paediatric obesity ${ }^{22}$. A ratio greater than 0.8 in women and 0.9 in men is associated with an increased risk of insulin resistance and associated disease ${ }^{23}$. Several studies have shown that waist circumference more than 90th percentile are more likely to have multiple risk factors ${ }^{7,18,24-26}$ In our study we have not found any association of waist circumference and waist hip ratio with metabolic syndrome. Surprisingly hip conference was higher in children with metabolic syndrome. We have found similar association of hip circumference with IGT in our previous study. ${ }^{10}$ This can be due to racial difference in fat distribution but needs further studies to comment. Moreover body proportion normally changes with age and may vary among different races and ethnic groups.

We found IGT, high triglyceride, systolic and diastolic hypertension and low HDL cholesterol to be associated with risk of metabolic syndrome as found in other studies. ${ }^{9,18}$ This is expected as these are components of metabolic syndrome. Insulin resistance index were higher in subjects with metabolic syndrome compared to those without metabolic syndrome but did not reach statistical significance. This may be due to the fact that serum level of insulin could be measured in a small number of subjects. Various studies among obese children and adolescents have found higher insulin resistance index to be important risk factor for metabolic syndrome. ${ }^{9,18}$

The present study has certain limitations. It was a crosssectional, clinic based study. Only obese children were included and it was not a case-control study. Risk factors for obesity were not identified. The prevalence of metabolic syndrome as found in our study can vary depending on various criteria used while defining paediatric metabolic syndorome.

We have found a high rate of metabolic syndrome in our obese subjects. Lifestyle modification can lead to reduction in the incidence of metabolic syndromere..$^{27,28,29}$ Obesity is of critical importance in the development of metabolic syndrome and needs to be prevented in childhood.

\section{References:}

1. Wang Y, Lobstein T. Worldwide trends in childhood overweight and obesity. Int J Pediatr Obes 2006;1:11-25.

2. Suwan L, Junjan AC, Puetpaiboon A. Increasing obesity in school children in a transitional society and the effect of weight control program. South East J Trop Med Pub Hlth1993; 24: 590-94. 
3. Alberti KG,Kimmet P,Shaw P.Metabolic Syndrome-a new worldwide definition.A consensus statement from the International Diabetic Federation.Diabet Med 2006;23:46980 .

4. Mohsin F, Tayyeb S, Baki A, Sarker S, Zabeen B, Begum T et al Prevalence of obesity among affluent school children in Dhaka. Mymensingh med J 2010 ;19:549-54.

5. Sinha R, Fisch G, Teague B,William V,Tamborlane WV,Banyas B et al.Prevalence of Impaird Glucose Tolerance among children and adolescents with marked obesity.N Engl J Med 2002;346:802-10.

6. Aggoun Y.Obesity,metabolic syndrome and cardiovascular disease. Pediatr Res 2007;61:653-59.

7. Cook S, Weitzman M, Auinger P,Nguyen M,William HD. Prevalence of a metabolic syndrome phenotype in adolescents. findings from the third National Health and Nutrition Examination Syrvey.1988-1994.Arch PediatrAdolesc Med 2003;157;821-27.

8. Cruz ML, Weigensberg MJ, Huang TT,Ball G,Shbi GQ,,Goran MI .The metabolic syndrome in overweight Hispanic youth and the role of insulin sensitivity. J Clin Endocrinol Metab2004;89:108-13.

9. Weiss R, Dziura J, Burgert TS, Tamborlane WV,TaksaliSE, YeckelCW et al.Obesity and the Metabolic Syndrome in Children and Adolescents.N Engl JMed 2004;350:2362-74.

10. Metabolic profile of obese children and adolescents in Bangladesh (Abstract). Mohsin F, Tayyeb S, Baki A, Zabeen B,Begum T, Azad K, Nahar N. Poster presentation at the 5the APPES scientific meeting (October 29-November 1,2008), Seoul, Republic of Korea

11. Kuczmarski RJ, Oglen CL, Grummer Strawn LM. 2000 CDC growth charts; United States. Washington DC:Center for Disease Control and Prevention/National Center for Health Statistics. Advance data 314:1-28.

12. The expert committee on the diagnosis and classification of diabetes Mellitus. Report of the expert committee on the diagnosis and classification of diabetes mellitus. Diabetes Care 1999;22:1:S5-9.

13. Mathews DR, Hosker JP,Rudenski AS,Naylor BA,Treacher DF,Turner RC. Homeostasis Model Assesment:Insulin resistance and beta cell function from fasting plasma glucose and insulin concentrations in man. Diabetologia 1985;28:41219.

14. Gillian S,Boyd BS, Joanna Koenigsberg BS,Falkner B,Gidding S,Hassink S. Effect of obesity and high blood pressure on plasma lipid levels in children and adolescents.Pediatrics 2005;116:442-46.

15. Third Report of the National Cholesterol Education program Expert Panel on Detection, Evaluation and Treatment of High
Blood Cholesterol in Adults (Adult treatment Panel III).Bethesda MD :National Heart, Lung and Blood Institute;2001.

16. Report of the second task force on Blood Pressure Control in Children-1987. National Heart, Lung and Blood Institute, Bethesda, MD. Pediatrics1987; 79:1-25.

17. DeFerranti SD,,Kimberlee G,Ludvig DS,Neufeld EJ, Newburger JW,Rifai N. Prevalence of the Metablic Syndrome in American Adolescents:Finding from the Third National Health and Nutrotion Examination Survey.Circulation 2004;110:2494-97.

18. Bustos P, Saez K,Gleisner A,Ulloa N,Calvo C,Asenjo S. Metabolic syndrome in obese adolescents.Pediatric Diabetes 2010;11:55-60.

19. Ford ES,Ajani UA,Mokdad AH . The metabolic syndrome and concentrations of C-reactive protein among U.S. youth. Diabetes Care 2005;28:878-81.

20. Saland JM, Update on the metabolic syndrome in children.Curr Opin Pediatr 2007;19:183-91.

21. Sayeed S,Banu A, Khanam PA,Alauddin S,Makbul S,Begum $\mathrm{T}$ et al. Prevalence of metabolic syndrome in three urban communities of Dhaka City. Ibrahim Med Coll J 2008;2: 448.

22. Shinomiya M, Ishikawa $Y$, Shiraj K. The significance of waisthip ratio in obese children. Int J Obes1990; 14:135

23. Caro J. Insulin resistance in obese and nonobese man. J Clin Endocrinol and Metab. 1991;73:692.

24. Bloch CA, Clemons P, Sperling MA. Puberty decreases insulin sensitivity. J Pediatr. 1987;110:481-87.

25. Ng VW, Kong AP, Choi KC,Ozaki R,Wong GW,So WY et al. $\mathrm{BMI}$ and waist circumference in predicting cardiovascular risk factor clustering in Chinese adolescents. Obesity. 2007;15:494-503.

26. Hirschler V,Calcagno ML,Aranda C,Maccallini G,Jadzinsky M.Can the metabolic syndrome identify children with insulin resistance? Pediatric Diabetes 2007;8:272-77.

27. Kang HS,Gutin B,Barbeau P,Owens S,Lemmon CR,Allison $\mathrm{J}$ et al.Physical training improves insulin resistance syndrome markers in obese adolescents.Med Sci Sports Exerc 2002 ;34:1920-27.

28. Ritenbaugh C,Teufel-Shone NI,Aickin MG,Jennie RJ,Poiriet S.Dillingham DC et al.A lifestyle intervention improves plasma insulin level among native American high school youth. Prev Med 2003;36:309-19.

29. Chen AK, Roberts CK, Barnard RJ. Effect of a short term diet and exercise intervention on metabolic syndrome in overweight children. Metabolism 2006;55:871-78. 